\title{
Monitoring of Daily Temperature Effect on Deck Deformation of Concrete Arch Bridge
}

\author{
Tang Yingying ${ }^{1,2}$, Wang Yong'e ${ }^{1}$, Niu Yanwei ${ }^{1}$, Chen Hong ${ }^{1}$ and Huang Pingming ${ }^{1}$ \\ ${ }^{1}$ School of Highway, Chang'an University, 710064 Xi'an, China \\ 2 School of Science, Chang'an University, 710064 Xi'an, China
}

\begin{abstract}
Temperature makes greatly differences on concrete in many aspects, including stress, strain and deformation, especially for arch concrete bridge structure. Some software can compute theoretical deformation, stress and bending moment of bridge structure due to temperature load, such as Midas Civil. In recent years, in order to learn about conditions of structure, many bridges have installed the healthy monitoring system. In this research, the monitoring data lasting approach a year was obtained from Haierwa Bridge, a concrete truss arch bridge, in Hebei province. The bridge belongs to Xuanda Highway, which undertook the main traffic flow of coal transportation. The proportion of heavy vehicles, exceeding 50t, ups to $30 \%$, different with common highway. The objective of this paper is to monitor and analyse the deformation of concrete truss arch bridge due to air temperature change. Firstly, results show that the daily tendencies of temperature and bridge vertical deformation at mid-span, L/4 and arch foot in the winter and summer. The linear relationship was calculated between the temperature and deformation of critical sections based on the monitoring data. In addition, the finite element model was established to calculate the theoretical value, and further compared with practice values.
\end{abstract}

\section{Introduction}

Solar heat transfer Heat is divided into convection, conduction and radiation, whose effect can be replaced by temperature in some degree in practice. Temperature change makes greatly differences on concrete in many aspects, including stress, strain and deformation. Some software can compute deformation, stress and bending moment of bridge structure due to temperature load, such as Midas Civil. Many scholars have studied influences on the concrete box girder, tower and other components of bridges. Researches not only concentrated on the temperature distribution of bridge components, but also investigated the behaviour of the bridge structures due to temperature change. Recently, in order to further investigate behaviour of bridges, the healthy monitoring system is more and more popular. Generally, the system was composed by several subsystems to monitor global performance, local performance and surrounding environment conditions.

On the one hand, many researches focus on the temperature distribution of critical bridge component. J. Suzuki et al. 1 focus on the pre-stressed concrete boxgirder bridge. They found that air temperature was higher than surface temperature during the night and opposite during the daytime. Lu Zhifang et al. 2 analysed environment temperature and relative humidity. The research provides a new reasonable and reliable method for creep effect analysis of steel-concrete composite continuous beam bridge and concrete bridge. Tian et al. 3 utilized the numerical method to get the quasi-static deformation of railway bridge resulted from temperature. Peiretti et al. 4 conducted experiment and found that temperature was uniform, linear variation and nonlinear distribution in concrete bridge deck based on a four-year temperature monitoring data. It is obvious that temperature makes great differences on stress, strain, bending moment, deformation and other behaviour of bridge structure.

On the other hand, temperature is an important and continuous input variable not only for bridge components but also for the entire structure. Shashi Moorty and Charles W. Roeder 5 analysed temperature-dependent bridge movement, suggesting that concrete bridges sometimes are designed for smaller temperature ranges and corresponding thermal movements than may be expected in practice. In Chinese, Zhou Guangdong and Yi Tinghua 6 proved that thermal load played a significant role in structural condition evaluation and bridge design procedure, especially for those statically indeterminate bridges and cable-supported bridges. Therefore, the temperature load has been taken into account in General Specifications for Design of Highway Bridges and Culverts 7. Other papers further studied the correlation between available thermal variables and deformation induced by thermal loading. Battista et al. 8 established a temperature-displacement model according to four type temperature data. It can be applied to 
estimate the bridge girder displacement. Xia et al. 9 analysed the temperature and structure data of a longspan suspension bridge. There was a linear correlation between temperature, displacement and stresses. GD zhou 10 proposed a general approach for modeling closed-form thermal correlation of deformation applied in a long-span arch bridge according to long-term monitoring data.

It is certain that temperature changing plays a role in deformation of concrete bridges. However, the attention pay on the whole bridge structure was not enough for all kinds of bridge structure, such as concrete truss arch bridge. The objective of this paper is to analyse the effect of temperature on bridge deck deformation, based on the temperature and deformation monitoring data of Haierwa Bridge. Moreover, the finite element model was established to calculate the theoretical value, and further compared with practice values.

\section{Bridge background}

\subsection{Bridge overview}

Xuanda Highway, namely xuanhua - datong highway, is one of the main channels for transporting coal from Datong to other places in Hebei Province. The Highway is started from xuanhua, via a Shaohua Ying, YangYuan to shanxi provincial boundary, whose total length is 127.8 $\mathrm{km}$. Xuanda Highway is the first mountainous area heavy highway in Hebei province. It is a two-way four-lane highway, with a speed limit range of $90 \mathrm{~km} / \mathrm{h}$ to 110 $\mathrm{km} / \mathrm{h}$.

The Haierwa Bridge (as figure 1) is located in the Xuanda Highway in Hebei province, nearly by Xuanhua. The number of the starting mileage pile is $\mathrm{K} 168+400$, and the terminal mileage pile is $\mathrm{K} 168+612$. The total length of bridge is $191.6 \mathrm{~m}$, and the width is $24.5 \mathrm{~m}$. It was completed and opened to traffic in December 2000. Bridge design span is combination of $14 m+138 m+10 m+2$ $\times 8 \mathrm{~m}$, which design load is car-20, trailer-120. The main span is composite truss arch bridge with pre-stressed concrete structure. The bridge is two-way four-lane. Especially, lane 3 and lane 4, from Datong to Xuanhua direction, are heavy traffic lanes of the heavy highway, regarded as the research object of the paper.

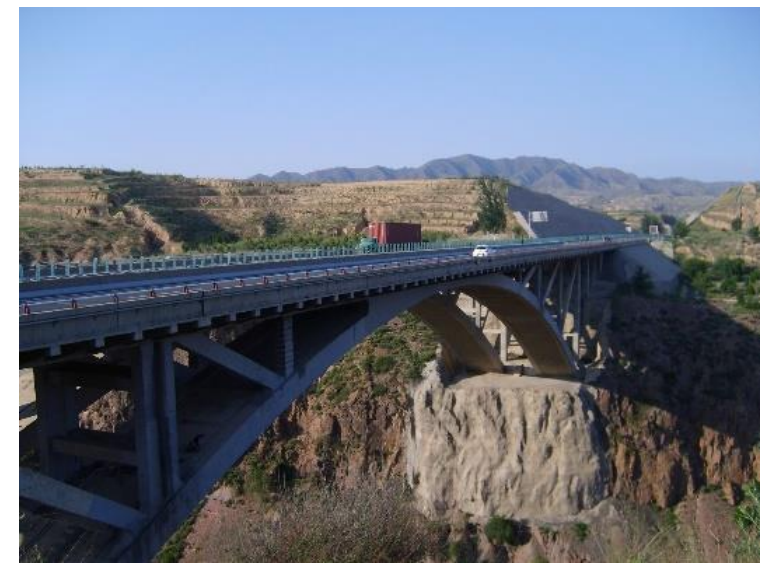

Figure 1. Haierwa Bridge

\subsection{Monitoring systems}

The healthy monitoring system was conducted to monitor the behaviours of the Haierwa Bridge. The bridge monitoring system consists of monitoring center and five monitoring subsystems to monitor dynamic characteristics, environment, traffic, deformation and stress-strain. It is total of 101 monitoring points installed on Haierwa Bridge. There were 24 stress-strain sensors installed along the main arch ring, which can also monitor the structure temperature. The research main used data collected from 5 displacement sensors and a corresponding air temperature sensors. Five displacement sensors were installed at five places on bridge deck, respectively above arch foot, 1/4 span and mid-span. Sensors numbers are 771018, 771012, 771011, 771004, 769204 as figure 2. While the air temperature sensors were placed on corresponding positions at 174411 (as figure 2) to monitor the air temperature, replaced the effect of solar heat transfer. The monitoring data to analyse the relationship between deformation and solar heat transfer is from March to November 2015, lasting for three seasons. The writer selected one day in the summer and winter respectively to show the daily distribution of temperature and deformation.

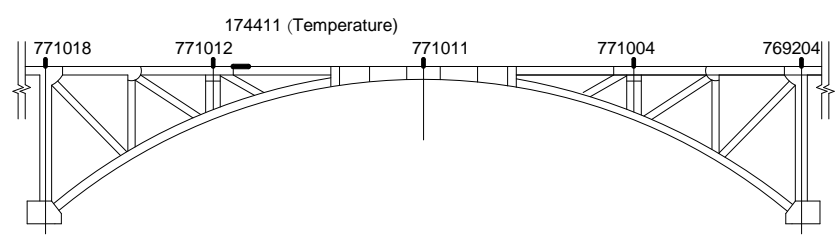

Figure 2. Sensors arrangement on Haierwa Bridge

The deck deformation sensors and air temperature sensors placement of Haierwa Bridge were as follows:

Table. 1 Sensors placement

\begin{tabular}{|c|c|c|}
\hline Type of sensor & $\begin{array}{l}\text { Number } \\
\text { of sensor }\end{array}$ & Placement \\
\hline \multirow{5}{*}{$\begin{array}{l}\text { Deformation } \\
\text { sensors }\end{array}$} & 771018 & $\begin{array}{l}\text { Arch foot on the side of } \\
\text { Datong }\end{array}$ \\
\hline & 771012 & $\mathrm{~L} / 4$ on the side of Datong \\
\hline & 771011 & Mid-span \\
\hline & 771004 & $\mathrm{~L} / 4$ on the side of Xuanhua \\
\hline & 799204 & $\begin{array}{c}\text { Arch foot on the side of } \\
\text { Xuanhua }\end{array}$ \\
\hline $\begin{array}{l}\text { Air temperature } \\
\text { sensors }\end{array}$ & 174411 & $\begin{array}{l}\text { Bridge deck of } \mathrm{L} / 4 \text { on the } \\
\text { side of Datong }\end{array}$ \\
\hline
\end{tabular}

\section{Thermal actions and deck deformation}

The air temperature sensor monitoring data was shown in figure 3, which presented the temperature tendency from March to October in 2015. The lowest temperature was $2{ }^{\circ} \mathrm{C}$ in March, and the highest temperature was $26.5{ }^{\circ} \mathrm{C}$ between June and August. Therefore, the temperature daily effect analysis used March 15th and August 5th monitoring data. The biggest different temperature value was 28.5 , which can be regarded as temperature load of finite element model. 


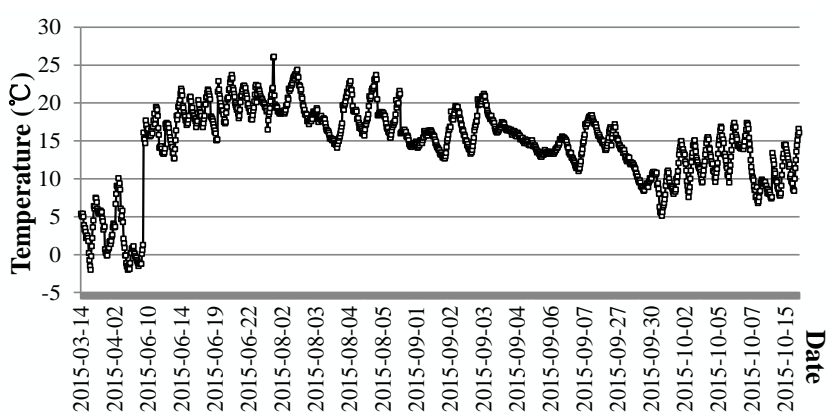

Figure 3. Temperature tendency in 2015

\subsection{Thermal actions in the winter}

Five critical positions were selected to analysis, including arch feet, 1/4 span and mid-span. It is symmetrical for the concrete truss arch bridge, so the following figures were presented by three critical sections. The deformation and air temperature conditions at mid-span was shown figure 4. The downward deflection is positive for all monitoring data. The curve of deflection is more stable than temperature.

The monitoring data on March 15th was selected to present the daily distribution in the winter. The picture shows that the deck deformation change of L/4 and arch foot was similar to the air temperature tendency. While the downward deflection of bridge mid-span decreased with temperature increasing in the winter, and increased with temperature declining. But there was a little delay between deformation and temperature. As for arch foot and $1 / 4$ span, the deflection upward increased with temperature decreasing. The different deformation values were respectively $11 \mathrm{~mm}, 6 \mathrm{~mm}, 4 \mathrm{~mm}$ for mid-span, $\mathrm{L} / 4$, arch foot, when temperature dropped about $12^{\circ} \mathrm{C}$.

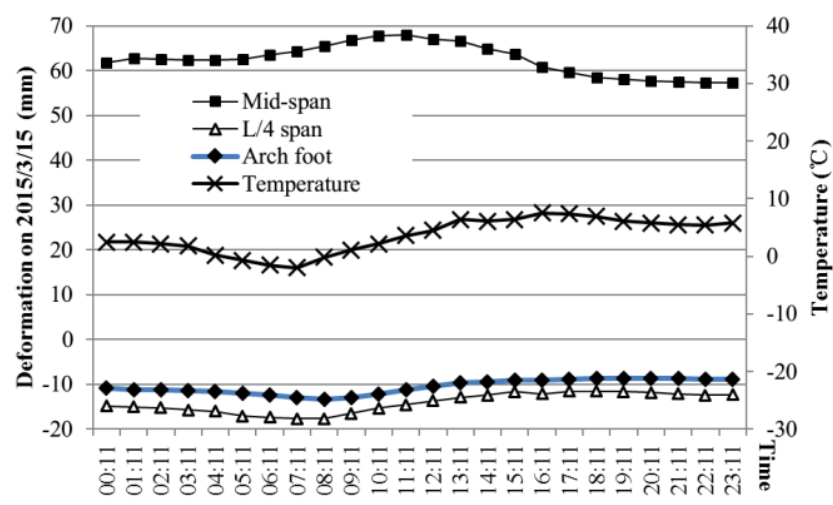

Figure 4. Deformation of arch bridge on 2015/3/15

\subsection{Thermal actions in the summer}

The monitoring data on August 5th was selected to present the daily distribution in the summer. The picture shows that the deck deformation change of L/4 and arch foot was similar to the air temperature tendency. However, the downward deflection of bridge mid-span decreased with temperature increasing in the summer. It needs to note that, the downward deformation is later than temperature decreased. As for arch foot and 1/4 span, the deflection upward increased with temperature increasing. The different deformation values were respectively $13 \mathrm{~mm}, 8 \mathrm{~mm}, 8 \mathrm{~mm}$ for mid-span, L/4, arch foot, when temperature dropped about $10^{\circ} \mathrm{C}$. In a word, the amplitude of temperature variation was smaller than that of winter, but the amplitude of deformation variation was larger in the summer.

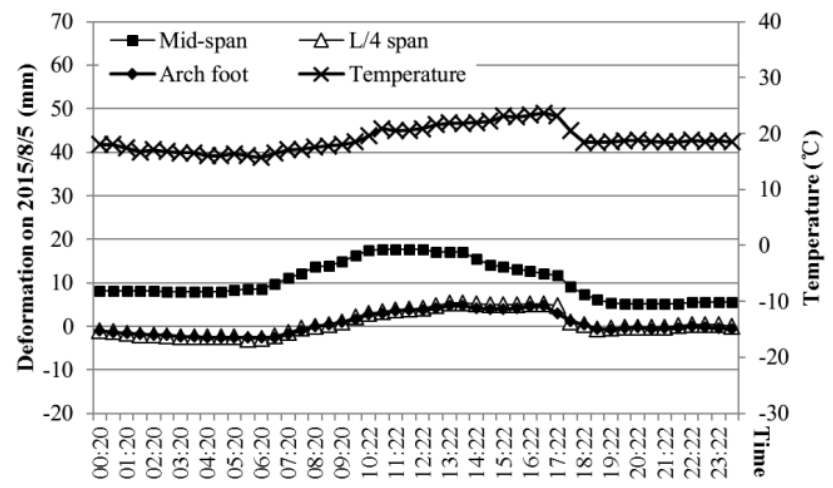

Figure 5. Deformation of arch bridge on 2015/8/5

\subsection{Linear relationships between temperature and deformation}

According to figure 4 and figure 5, there were strong relationship between temperature and deformation, which need to further investigation. All monitoring data in 2015 was spotted to regress the linear relationship. As shown in figure 6 , the temperature effect on deck deformation was biggest at mid-span. Although the correlation coefficient was not enough, only was 0.75 . As for arch foot and 1/4 span (figure 7 and 8), the deflection upward increased with temperature decreasing. The relationship between deflection and temperature change is linear, and the correlation coefficient can exceed 0.9 when the temperature higher than $10^{\circ} \mathrm{C}$. In other words, the linear relationship was weak under $10^{\circ} \mathrm{C}$. The slopes of temperature-deflection are 1.1, 1.3 and -2.3 at arch foot, $1 / 4$ span and mid span, respectively. It proved that temperature effect on mid-span deformation was much more than L/4 and arch foot.

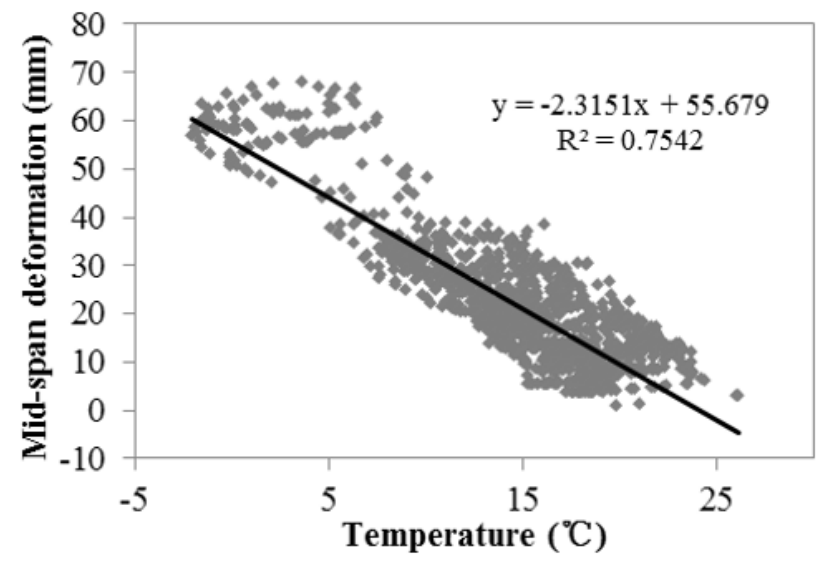

Figure 6. Relationship between deformation and temperature of mid-span 


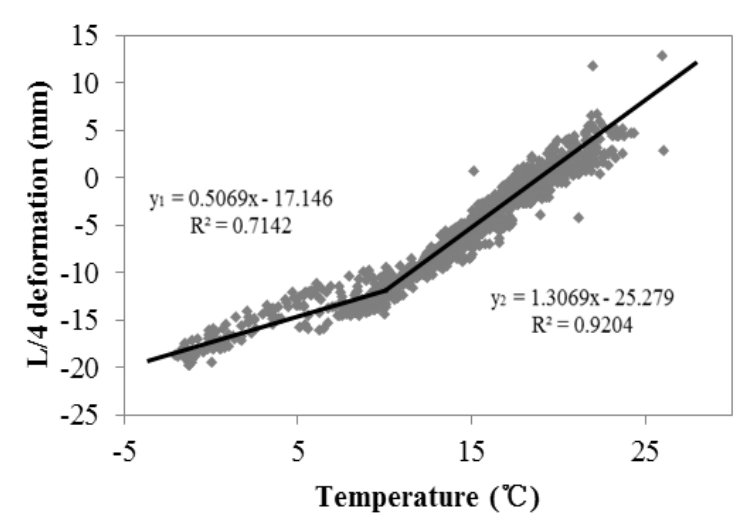

Figure 7. Relationship between deformation and temperature of $\mathrm{L} / 4$

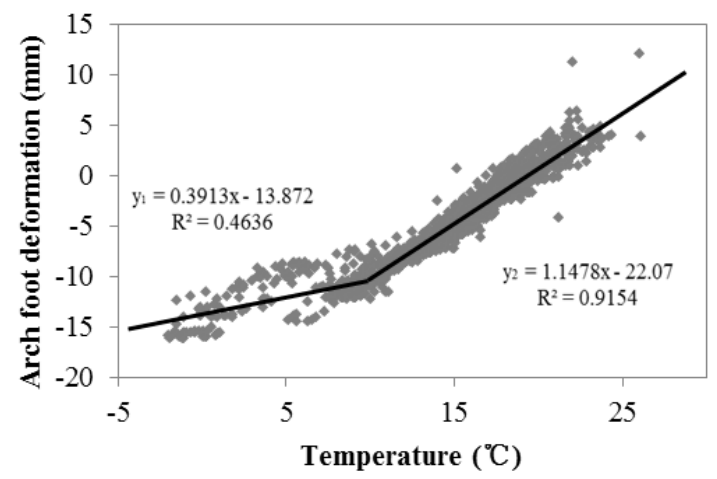

Figure 8. Relationship between deformation and temperature of arch foot

\subsection{Verification of Finite Element}

Haierwa Bridge is a concrete truss arch bridge. The main span is up to $138 \mathrm{~m}$. There are double columns on the main arch at L/4 span, and expansion joint is between the two columns, which is different from common truss arch bridges. In order to verify the rule got from monitoring data above, the write establish the finite element (FE) model of the bridge. The FE model has 408 nodes and 414 beam elements. The concrete selected C50 to simulate. At the same time, the corresponding temperature load was applied to Midas Civil to obtain theoretical deflection value as figure 9. Because the traffic load and self-weight of bridge are stable respectively and always existence, the write only take temperature load into the model. Compared with the monitoring data, most of the deformation of mid-span bridge is led by the change of temperature.

As table 2 shown, the deformation growth rate was obtained due to temperature changing based on regression equation. It is obvious that the deformation of mid-span is far more than L/4 span and arch foot. The conclusion is similar to the FE model. But the deformation growth rate is different. In all monitoring data, the maximum temperature is $26.5{ }^{\circ} \mathrm{C}$ and the minimum temperature is $-2{ }^{\circ} \mathrm{C}$. Therefore, the biggest different value of air temperature can up to $28.5^{\circ} \mathrm{C}$. According to regression equation of monitoring data, the deck of mid-span declined $6.598 \mathrm{~cm}$, while the theoretical was $8.623 \mathrm{~cm}$. The deflection is stable from arch foot to $1 / 4$ span with temperature changing, which is not exceed $1 \mathrm{~cm}$ in the finite element model. However, the monitoring data were about $2 \sim 3 \mathrm{~cm}$, and the direction is different. In other words, when temperature dropping, the practical downward deformation will much over than the nominal data at L/4 and arch foot. However the mid-span different deformation is opposite. In conclusion, there were about $2 \sim 3.5 \mathrm{~cm}$ different deformation value between theoretical and monitoring data. The different may be led by shrinkage, creep, material property, traffic conditions and others, which need to be further studied.

Table. 2 Comparison of monitoring data and theoretical value

\begin{tabular}{|c|c|c|c|c|}
\hline \multicolumn{2}{|c|}{$\begin{array}{l}\text { Correlation of } \\
\text { temperature and } \\
\text { deformation }\end{array}$} & \multirow{3}{*}{$\begin{array}{c}\text { Mid-span } \\
d=-2.3151 \Delta t\end{array}$} & \multirow{2}{*}{$\begin{array}{c}\text { L/4 span } \\
d=1.3069 \Delta t\end{array}$} & \multirow{2}{*}{$\begin{array}{l}\text { Arch foot } \\
d=1.1478 \Delta t\end{array}$} \\
\hline \multirow{2}{*}{$\begin{array}{l}\text { Monitori } \\
\text { ng data }\end{array}$} & \multirow{2}{*}{ 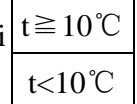 } & & & \\
\hline & & & $\mathrm{d}=0.5069 \Delta \mathrm{t}$ & $\mathrm{d}=0.3913 \Delta \mathrm{t}$ \\
\hline \multicolumn{2}{|c|}{ FE model } & $\mathrm{d}=-3.028 \Delta \mathrm{t}$ & $\mathrm{d}=-0.2517 \Delta \mathrm{t}$ & $\mathrm{d}=-0.2567 \Delta \mathrm{t}$ \\
\hline \multicolumn{2}{|c|}{$\Delta \mathrm{T}\left({ }^{\circ} \mathrm{C}\right)$} & $-2 \sim 26.5$ & $-2 \sim 26.5$ & $-2 \sim 26.5$ \\
\hline \multicolumn{2}{|c|}{$\begin{array}{l}\text { Monitoring value } \\
(\mathrm{cm})\end{array}$} & 6.598 & -2.751 & -2.300 \\
\hline \multicolumn{2}{|c|}{$\begin{array}{l}\text { FE theoretical } \\
\text { value }(\mathrm{cm})\end{array}$} & 8.623 & 0.717 & 0.732 \\
\hline \multicolumn{2}{|c|}{$\begin{array}{l}\text { Different value } \\
\qquad(\mathrm{cm})\end{array}$} & 2.027 & 3.468 & 2.080 \\
\hline
\end{tabular}

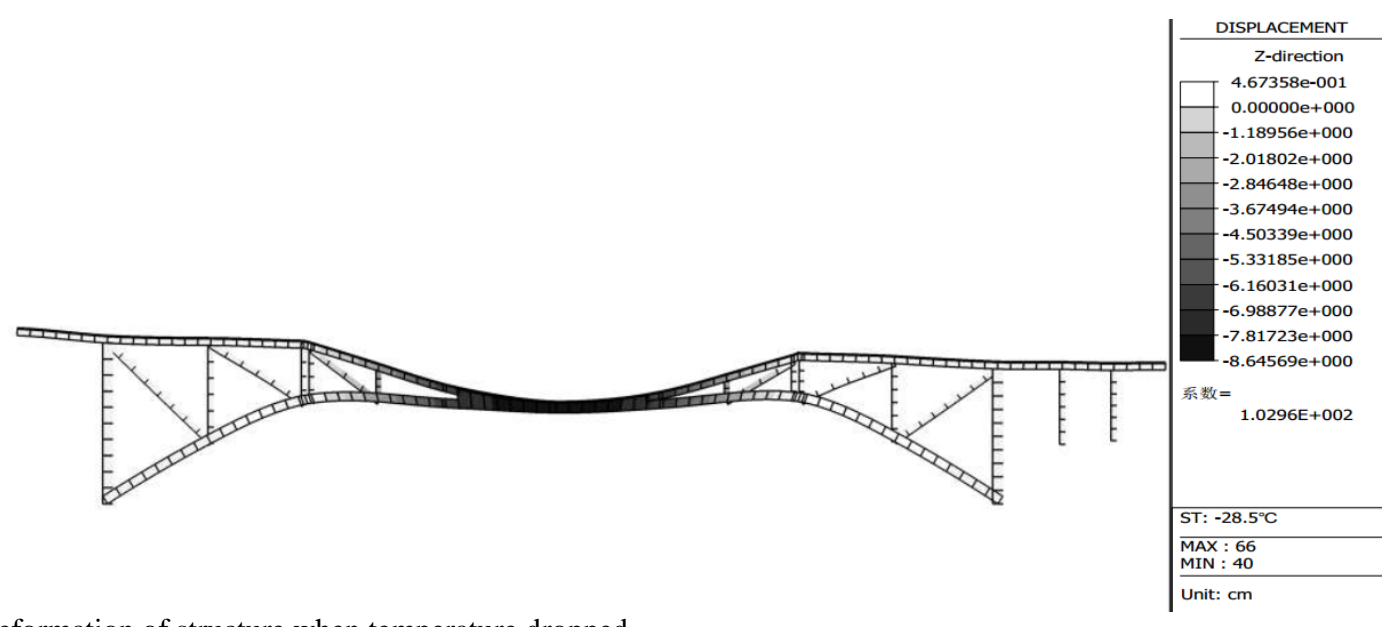

Figure 9. Deformation of structure when temperature dropped 


\section{Conclusions}

In conclusion, air temperature change has influence on structure deformation in concrete arch bridge, especially for mid-span. There is a strong linear relationship between the structure deformation and temperature. Combined with the finite element model, conclusions were as follows:

Deformation curves were more stable than the temperature curve. For instance, some small fluctuations of temperature were not reflected at the same time.

The deck deformation varied with temperature. The deck deformation change of $\mathrm{L} / 4$ and arch foot was similar to the air temperature tendency, while there was a little delay between deformation and temperature. The downward deflection of bridge mid-span decreased with temperature increasing, and increased with temperature declining. In addition, the amplitude of temperature variation was smaller than that of winter, but the amplitude of deformation variation was larger in the summer.

There were strong linear relationships between air temperature and deck deformation at L/4 and arch foot of concrete truss arch bridge. As for mid-span, the linear relationship is weaker. However, the temperature effect on mid-span deformation was much more than $\mathrm{L} / 4$ and arch foot.

In addition, the finite element model was established to calculate the theoretical value, and further compared with practice values. There were about $2 \mathrm{~cm}$ different deformation value between theoretical and monitoring data. It is essential to control deformation due to temperature change for concrete arch bridge, especial its middle span in long term operation.

\section{Acknowledgments}

This study is supported by the National Science Foundation of PR China (51208056), and the Fundamental Research Funds for the Central Universities (310821161013, 300102218213).

\section{References}

1. J. Suzuki, Y. Ohba, Y. Uchikawa, K. Hoshikawa and K. Kimura, Monitoring temperatures on a real boxgirder bridge and energy budget analysis for basic information on bridge cooling and surface freezing, $\mathrm{J}$. Bridge Eng., 12, 7 (2007)

2. Z Lu, M Liu and Q Li, Creep effect analysis of steelconcrete composite bridge considering mutative temperature and relative humidity, J. Central South University, 46, 2650-2657 (2015)

3. Y Tian, $\mathrm{N}$ Zhang and $\mathrm{H} \mathrm{Xia,} \mathrm{Temperature} \mathrm{effect} \mathrm{on}$ service performance of high-speed railway concrete bridges, Adv. Struct. Eng., 20, (6) 865-883 (2017).

4. H. C. Peiretti, J. I. E. Parrotta, A. B. Oregui, A. P. Caldentey and F. A. Fernandez, Experimental study of thermal actions on a solid slab concrete deck bridge and comparison with Eurocode $1 \mathrm{~J}$. Bridge Eng., 19, 10 (2014)

5. S. Moorty and C. W. Roeder, Temperature-dependent bridge moment, J. Struct. Eng., 118, 1090-1105 (1992)

6. GD Zhou and TH Yi, Thermal load in large-scale Bridges: a state-of-the-art review, Int. J. Distrib. Sens. N., 17 (2013)

7. CCCC Highway consultants CO. Ltd. General Code for Design of Highway Bridges and Culverts (China Communications Press, Beijing, 2004)

8. N. D. Battista, J. D. Brown, H. P. Tan and K. Y. Koo, Measuring and modelling the thermal performance of the Tamar Suspension Bridge using a wireless sensor network, Struct. Infrastruct. E., 11, 176-193 (2015)

9. Q Xia, J Zhang, YD Tian and YF Zhang, Experimental study of thermal effects on a long-span suspension bridge, J. Bridge Eng., 22, 7(2017)

10. GD Zhou, TH Yi, B Chen and X Chen, Modeling deformation induced by thermal loading using longterm bridge monitoring data, J. Perform. Constr. Facil., 32, 3 (2018) 